\title{
BMJ Open Secular trends in postpartum weight retention from 2003 to 2012: a nationwide, population-based, retrospective, longitudinal study in South Korea
}

\author{
Yoonjung Yoonie Joo (1) , ${ }^{1}$ Jong Heon Park, ${ }^{2}$ Sangbum Choi, ${ }^{3}$ Geum Joon Cho ${ }^{4}$
}

To cite: Joo YY, Park JH, Choi S, et al. Secular trends in postpartum weight retention from 2003 to 2012: a nationwide, population-based, retrospective, longitudinal study in South Korea. BMJ Open 2020;10:e034054. doi:10.1136/ bmjopen-2019-034054

- Prepublication history and additional material for this paper are available online. To view these files, please visit the journal online (http://dx.doi. org/10.1136/bmjopen-2019034054).

Received 05 September 2019 Revised 29 April 2020

Accepted 29 May 2020

Check for updates

(C) Author(s) (or their employer(s)) 2020. Re-use permitted under CC BY-NC. No commercial re-use. See rights and permissions. Published by BMJ.

${ }^{1}$ Feinberg School of Medicine, Northwestern University,

Chicago, Illinois, USA

${ }^{2}$ Big Data Steering Department, National Health Insurance

Service, Wonju-si, Gangwon-do, Republic of Korea

${ }^{3}$ Department of Statistics, Korea University, Seongbuk-gu, Seoul, Republic of Korea

${ }^{4}$ Department of Obstetrics and Gynecology, Korea University Guro Hospital, Korea University College of Medicine, Seoul, Republic of Korea

Correspondence to

Dr Geum Joon Cho;

geumjoon@korea.ac.kr

\section{ABSTRACT}

Objective To assess the secular trends in postpartum weight retention (PWR) over a decade with the populationbased risk factors.

Design Retrospective cohort study.

Setting A national health screening examination data provided by the National Health Insurance Service in South Korea.

Participants 130551 women who delivered babies between 1 January 2003 and 31 December 2012 and who underwent a national health screening examination 1 to 2 years prior to delivery and within 1 year after delivery. Methods Their PWR were determined during the study period of 2003-2012. We fitted logistic regression and linear mixed models to assess the independent contribution of PWR to obesity after adjusting for potential confounders.

\section{Primary and secondary outcome}

measures Prepregnancy and postpartum weight and body mass index (BMI).

Results The adjusted PWR increased from mean value of $2.02 \mathrm{~kg}$ in $2003(95 \% \mathrm{Cl} 1.88$ to 2.15$)$ to $2.79 \mathrm{~kg}$ in 2012 (95\% Cl 2.73 to 2.84) ( $p$ value for trend $<0.01$ ), after adjusting potential confounders including age, prepregnancy time, postpartum time, prepregnancy BMI, income and smoking status. The risk for a PWR of more than $5 \mathrm{~kg}$ also increased over the study period.

Conclusions Secular increases in PWR have been significantly observed between 2003 and 2012 for childbearing women. It is necessary to identify risk factors contributing to the observed increase and develop effective strategies to address the heightened risk for PWR.

\section{INTRODUCTION}

The worldwide incidence of obesity has risen significantly in recent decades, ${ }^{1}$ and obesity has become a major concern in all populations, including among women of reproductive age. ${ }^{2}$ Pregnancy itself has been suggested to contribute to the development of obesity through subsequent long-term weight retention $^{3-6} ; 10 \%-15 \%$ of pregnant women may retain weight gained during pregnancy and
Strengths and limitations of this study

- This will be the first nationwide population-based cohort study to evaluate secular trends in postpartum weight retention (PWR) and their potential risk factors.

- To date, the secular trend of PWR has been poorly investigated due to varying study designs, ethnic composition and clinical definitions of PWR.

- The study was conducted on a large longitudinal cohort of 130551 female individuals with a singular ethnic origin.

- All research data were retrieved from the national centralised database of health examination records in a standardised manner.

- The body weight of every research participant was regularly and objectively measured by the National Health Screening Examination, using anthropometric parameters, avoiding measurement bias and false-positive findings.

eventually become obese. ${ }^{5}$ The concept of postpartum weight retention (PWR) provides a vital account of women's health and obesity.

PWR is defined as the difference between prepregnancy weight and weight at some time after delivery. Previous studies have identified the average PWR value ranging from $1 \mathrm{~kg}$ to $20 \mathrm{~kg}$ worldwide. ${ }^{48}$ The large span of this range may be attributable to differing study designs, ethnic populations and definitions of PWR. However, pregnant women who have high prepregnancy weights and excessive gestational weight gain (GWG) are consistently identified as having a high risk for PWR. ${ }^{3479}$ A number of other risk factors have been reported, including smoking status, breast feeding, dietary intake, lack of physical activity, maternal income, age, education and parity. ${ }^{8}{ }^{10-15}$ Thus, the large discrepancies in PWR between studies may also result 
from differences in the distributions of these risk factors among study populations.

Recent studies have documented changes in the prevalence of known risk factors for PWR. The prevalence of prepregnancy obesity has increased by an average of $0.5 \%$ per year from 2003 to $2009,{ }^{16}$ and the worldwide smoking population has also increased steadily. ${ }^{17}$ Moreover, from 2000 to 2009, the percentage of pregnant women whose weight gains are in line with Institute of Medicine recommendations decreased slightly, while the mean GWG increased slightly. ${ }^{18}$ Additionally, the breastfeeding initiation rate has increased significantly, partially due to the increased awareness of pregnancy and parenting education recently, which is known to benefit mothers by lowering the risk of obesity. ${ }^{19}{ }^{20}$ However, it is unclear whether these changes in risk factors in fact influence trends in PWR.

In this study, we analysed a large longitudinal cohort of 130551 female individuals through the Republic of Korea's national health records to determine PWR changes from 2003 to 2012. The aim of this study was to investigate secular trends in PWR and their contributing risk factors, providing essential evidence for the design of targeted interventions to prevent excessive PWR.

\section{METHODS}

\section{Study population and data}

The Korean National Health Insurance Service (NHIS) provides mandatory health insurance for all South Koreans, approximately 50 million individuals. All insurance subscribers and dependents are invited to participate in the National Health Screening Examination (NHSE), which consists of two components, a health interview survey and a physical examination. The medical institutions for conducting NHSE are required to fully comply with the Framework Act on Health Examinations, which meet national standards of manpower, medical facilities and equipment. The NHSE is generally taken at least once every 2 years for all Korean citizens, and the participation rate of NHSE was $74.8 \%$ out of the entire Korean population in $2014 .^{21}$

Being built by the single insurer, NHIS, the Korean National Health Insurance (KNHI) claims that database is a centralised data repository containing nearly all claims of medical services provided from Korean healthcare providers, with the exception of procedures not covered by health insurance, such as cosmetic surgery. We selected study participants through merging the KNHI claims with the NHSE database.

Using the KNHI claims database, we identified all women who had delivered babies between 1 January 2003 and 31 December 2012. Of these, only women who had undergone an NHSE 1 to 2 years prior to delivery for the evaluation of prepregnancy characteristics and again within 1 year after delivery for the assessment of their postpartum characteristics were included in analyses.
Determination of prepregnancy and postpartum characteristics

We obtained prepregnancy and postpartum characteristics of the participants from the KNHI claims and NHSE databases, and data on smoking status from the health interview component of the NHSE. We categorised participants into current smokers, past smokers and nonsmokers and their health examination included prepregnancy weight and body mass index (BMI).

PWR was determined from health examination data by subtracting weight at the prepregnancy visit from weight at the postpartum visit. We defined two time intervals, prepregnancy time and postpartum time, as the time from prepregnancy examination to delivery and the time from first delivery to postpartum examination, respectively.

As the health insurance premiums in the KNHI claims database reflect employee salaries, these premiums were used as a proxy for income level. Prepregnancy insurance premiums were categorised into five quintiles, with Q1 being the lowest income level and Q5 being the highest.

\section{Statistical analyses}

Continuous variables are expressed as means $\pm \mathrm{SD}$, and categorical variables as percentages. We compared clinical and demographic characteristics among groups using analysis of variance (ANOVA) for continuous variables and the $\chi^{2}$ test for categorical variables. Then, we determined secular trends in continuous and categorical variables and compared them across years using the ANOVA polynomial regression test and the $\chi^{2}$ Cochran-Armitage test, respectively. We estimated adjusted PWRs and trends over time using analysis of covariance (ANCOVA) with adjustment for covariates including age, prepregnancy BMI, smoking status, insurance premiums, prepregnancy time and postpartum time. The covariates were selected based on the previous literature and the information availability within our dataset. To estimate the adjusted OR and $95 \%$ CI for having a PWR of more than $5 \mathrm{~kg},{ }^{22}$ we used multivariate logistic regression analysis. We did not consider general weight trends in the population as covariates since no statistically significant weight trends have been confirmed in general Korean population for 2003-2012. ${ }^{23}$

Notably, timing-related variation may not be properly reflected in ANOVA or ANCOVA methods. It should be noted that data collection occurred at different timepoints for each individual, although the total range of measurement times was not more than 1 year. In order to adjust for discrepancies in measurement periods and other potential confounders, we used a linear mixedeffects model (LMM) that incorporated year at delivery and period of weight measurement (centred on birth as 0 ) as their main covariate effects. $\mathrm{LMMs}^{24}$ are an extension of linear models that are particularly useful in settings where repeated measurements are made on the same subject, such as longitudinal studies, or where measurements are made on clusters of related statistical units. The core concept of LMM is that it incorporates 
both fixed effects (a set of conventional covariates) and random effects to allow for potential correlation within each individual. Our LMMs also included as fixed effects participant age at birth, BMI prior to giving birth, income level and smoking status. Effect modification was evaluated by adding a single random effect for the weight level specific to each individual.

All tests were two sided, and we considered a $\mathrm{p}$ value $<0.05$ statistically significant. We then performed statistical analyses through SPSS (V.17 edition) and R environment (V.3.4.4) with the lme4 library. ${ }^{25}$

\section{Patient and public involvement}

Patients or the public were not involved in the design, or conduct, or reporting, or dissemination of our research.

\section{RESULTS}

The final cohort comprised a total of 130551 participants with data collected between 2003 and 2012. Table 1 summarises their basic characteristics according to the year of delivery. Age at delivery, prepregnancy weight, postpartum weight and rate of prepregnancy obesity all tended to increase over time. In particular, the 2003 mean prepregnancy and postpartum weights of $52.05 \pm 6.19(\mathrm{~kg})$ and $53.92 \pm 6.90(\mathrm{~kg})$, respectively, increased to $53.58 \pm 7.15$ $(\mathrm{kg})$ and $56.41 \pm 8.19(\mathrm{~kg})$ in 2012. Distributions of income levels and smoking status also differed and increased over time.

Table 2 shows PWR, determined by subtracting the prepregnancy weight from the postpartum weight for each year, according to the year of delivery. The PWR increased significantly from $1.88 \mathrm{~kg}$ in 2003 to $2.83 \mathrm{~kg}$ in 2012 ( $\mathrm{p}$ value for trend $<0.01$ ).

Since PWR may be affected by potential risk factors, we also computed the adjusted PWR using multivariate linear regression to adjust for all characteristics from table 1: age, prepregnancy time, postpartum time, prepregnancy $\mathrm{BMI}$, income and smoking status. The adjusted PWR also increased from $2.02 \mathrm{~kg}$ in 2003 to $2.79 \mathrm{~kg}$ in 2012 ( $\mathrm{p}$ value for trend $<0.01$ ), with a marginal ratio of 1.38 .

Table 3 shows the number of women who changed BMI category between prepregnancy and postpregnancy timepoints. $16.5 \%$ (18 826 out of 114322 women) of normal weight women shifted BMI category to either overweight or obese, and $45.7 \%$ (4675 out of 10237 women) of overweight women shifted BMI category to obese after pregnancy. $85.5 \%$ of women with obesity stayed at the same BMI category of obese after pregnancy.

We applied multivariate logistic regression analysis to evaluate the contributions of risk factors to having a PWR of more than $5 \mathrm{~kg}$. Potential confounders were adjusted for both individually and collectively, producing crude and adjusted ORs (table 4). Overall, the risk of PWR greater than $5 \mathrm{~kg}$ was higher in 2012 than in 2003 (adjusted OR, $1.440 ; 95 \%$ CI 1.296 to 1.604$)$. This increased risk was associated with prepregnancy BMI, lowest incomes and past and current smoking status. In contrast, age and high income were associated with decreased risk.

After we adjusted for variation in collection times, the average weight of participants in the reference group (those who are $\leq 30$ years, in the middle income quintile, delivered in 2003, and non-smokers) was $53.2 \mathrm{~kg}$ (95\% CI 53.0 to 53.6; table 5). Weight tended to increase with age and decrease with rising income level; it was also positively associated with past or current smoking status. Most importantly, weight consistently increased across the study period. For example, women who delivered in 2012 gained an average of $2.23 \mathrm{~kg}$ (95\% CI 1.93 to 2.52 ) more than those who delivered in 2003. More abstractly, if the interval between collection of prepregnancy and postpartum weights was 1 year, participants gained an average of $1.28 \mathrm{~kg}$ ( $95 \%$ CI 1.27 to 1.29 ).

\section{DISCUSSION}

\section{Main findings}

In this study, we evaluated the secular trends in PWR among 130551 Korean women who gave birth between 2003 and 2012, using nationwide health insurance data. The results of this investigation showed a significant increase in PWR over the studied decade, even after adjusting for several confounding factors. We also observed that the risks of PWR greater than $5 \mathrm{~kg}$ significantly increased over the study period.

Our study also assessed risk factors that were specific to PWR greater than $5 \mathrm{~kg}$ and found that high prepregnancy BMI and smoking status were associated with an increased risk of PWR greater than $5 \mathrm{~kg}$. These results are consistent with the findings of other studies. ${ }^{26}$ We also found that compared with the middle-income group, the lowest income group had a slightly increased risk of PWR greater than $5 \mathrm{~kg}$ whereas the highest income group had a slightly decreased risk; this finding is also consistent with the results from other studies. ${ }^{15222627}$ Although the exact reasons for the association between high PWR and income remains unknown, a more detailed investigation may provide useful information for reducing PWR.

\section{Strengths}

The current study is the first to evaluate secular trends for PWR within an ethnically homogenous population. The greatest strength of our study is that it was a largescale, long-term follow-up study with a duration of 10 years that was conducted on participants with a singular ethnic origin. In addition, we used objective anthropometric parameters that were regularly measured by the NHSE, avoiding the possibility that participants may have underestimated their weights, which is inherent to selfreporting methods. ${ }^{28}$

The centralised clinical database of health examination records offered an effective way to investigate populationbased trends with reliability, validity and standardisation. To our knowledge, there are currently no equivalent population-based studies that examine PWR trends; 


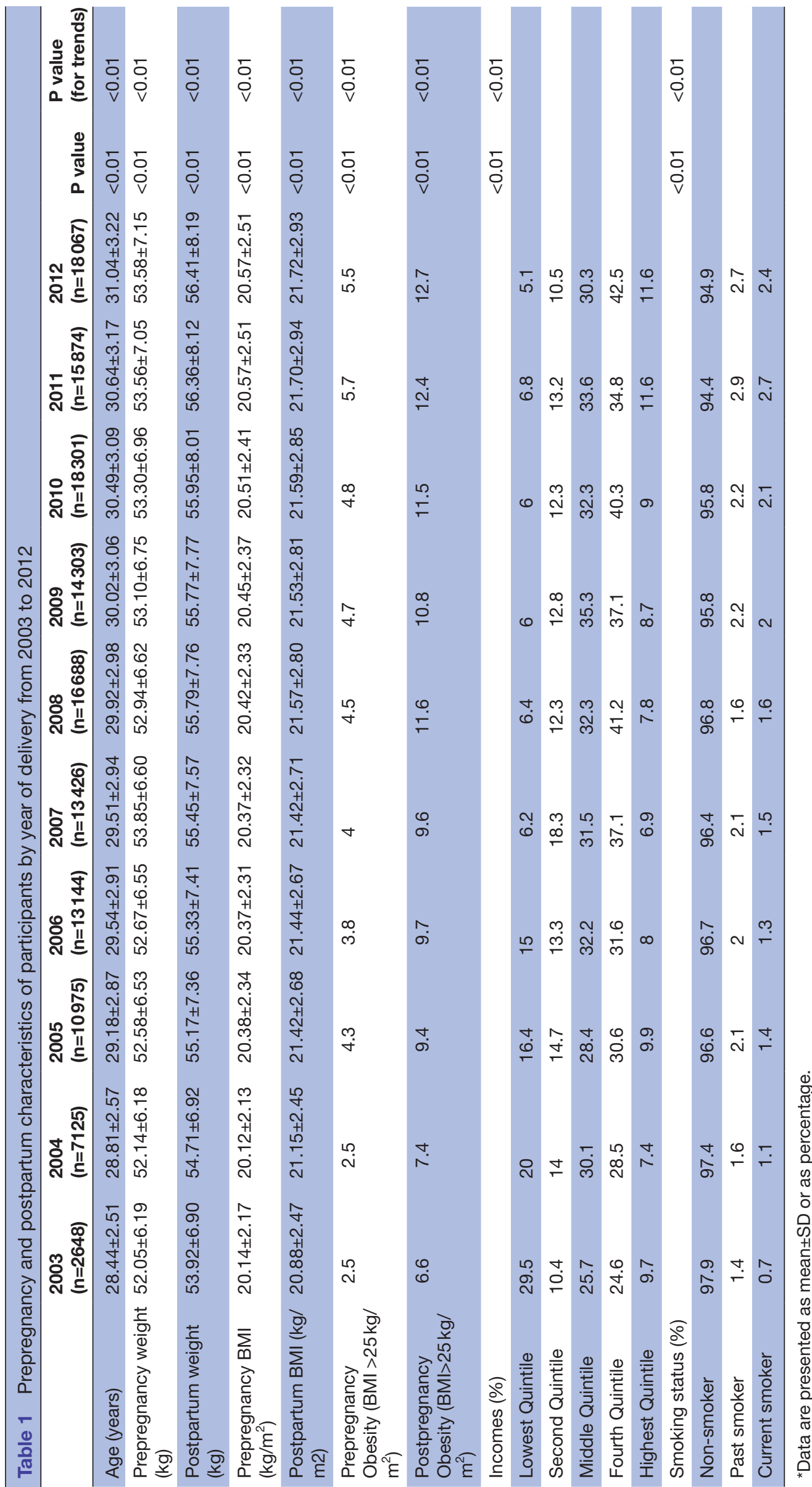


Table 2 Secular trends in postpartum weight retention (PWR) according to year of delivery

\begin{tabular}{|lcc|}
\hline & PWR & Adjusted PWR \\
\hline 2003 & $1.88 \pm 3.49(1.75$ to 2.01$)$ & $2.02(1.88$ to 2.15$)$ \\
\hline 2004 & $2.57 \pm 3.67(2.48$ to 2.65$)$ & $2.28(2.20$ to 2.37$)$ \\
\hline 2005 & $2.60 \pm 3.79(2.52$ to 2.66$)$ & $2.41(2.35$ to 2.48$)$ \\
\hline 2006 & $2.66 \pm 3.78(2.59$ to 2.72$)$ & $2.45(2.39$ to 2.51$)$ \\
\hline 2007 & $2.60 \pm 3.88(2.54$ to 2.67$)$ & $2.50(2.44$ to 2.56$)$ \\
\hline 2008 & $2.85 \pm 3.98(2.79$ to 2.91$)$ & $2.70(2.65$ to 2.75$)$ \\
2009 & $2.67 \pm 4.00(2.61$ to 2.74$)$ & $2.57(2.51$ to 2.62$)$ \\
\hline 2010 & $2.65 \pm 4.01(2.59$ to 2.71$)$ & $2.57(2.51$ to 2.61$)$ \\
\hline 2011 & $2.80 \pm 4.15(2.73$ to 2.86$)$ & $2.75(2.70$ to 2.80$)$ \\
\hline 2012 & $2.83 \pm 4.18(2.77$ to 2.89$)$ & $2.79(2.73$ to 2.84$)$ \\
\hline $\begin{array}{l}\text { P value for } \\
\text { trends }\end{array}$ & $<0.01$ & $<0.01$ \\
\hline
\end{tabular}

PWR, postpartum weight retention.

*Adjusted for age, prepregnancy time, postpartum time, prepregnancy body mass index, income and smoking status. Data are presented as mean \pm SD in the left column and mean value in the right column $(95 \% \mathrm{Cl})$. This regression analysis is performed each year separately.

thus, comparisons with other ethnic populations or over different time periods are difficult to make. Variations in study features such as the timing of body weight measurements relative to delivery and the biological races of participants should be noted for comparisons with future PWR research.

\section{Limitations}

Due to cohort constraints, our study population was limited to the Korean population and cannot provide a comprehensive review of the global trends in PWR. Our results must therefore be interpreted with caution. Compared with Western European women, significantly more South Asian, Middle Eastern and African women have high PWRs. ${ }^{29}$ Moreover, Korean women tend to have higher GWG and PWR than women in other Asian countries. ${ }^{30}$ Therefore, further research is necessary to determine whether our results can be applied to other ethnic groups.

\begin{tabular}{llll}
\hline $\begin{array}{l}\text { Table } 3 \\
\text { The number of participants who changed body } \\
\text { mass index (BMI) category between prepregnancy and } \\
\text { postpregnancy timepoints }\end{array}$ \\
\begin{tabular}{llll} 
Prepregnancy BMI & \multicolumn{1}{l}{ Postpregnancy BMI (N=130517) } \\
\cline { 2 - 4 } (N=130541) & Normal & Overweight & Obese \\
\hline Normal & $95496(73.2 \%)$ & $14446(11.1 \%)$ & $4380(3.4 \%)$ \\
Overweight & $1575(1.2 \%)$ & $3987(3.1 \%)$ & $4675(3.6 \%)$ \\
Obese & $184(0.1 \%)$ & $676(0.5 \%)$ & $5088(3.9 \%)$
\end{tabular}
\end{tabular}

*BMI was grouped into normal weight $\left(<23.0 \mathrm{~kg} / \mathrm{m}^{2}\right)$, overweight $(23.0-$ $\left.24.9 \mathrm{~kg} / \mathrm{m}^{2}\right)$, obese $\left(\geq 25.0 \mathrm{~kg} / \mathrm{m}^{2}\right)$ according to the WHO Western Pacific Region guideline.
Other limitations of our study include the timing of prepregnancy and postpartum weight measurements, which differed among individual participants and across study periods, and may have affected the observed trends in PWR. We used logistic regression and LMMs to adjust for these differences in measurement times, as well as for other risk factors. Notably, LMMs directly account for the different timing of prepregnancy and postpartum weight measurements and also provide easy-to-read outputs. Both models confirmed the increasing trend in PWR across the study period.

Also, some information of potential risk factors were not fully available in the study dataset, thus could not be reflected in the analysis. For instance, parity, education level, physical activity, breastfeeding status or diet could be important confounders to consider for the PWR trends, but could not be tested in our analysis due to the limited availability of the information. The sequence information of each pregnancy was limited as well. The women who had multiple pregnancies during the study period were included in the analysis regardless of their pregnancy frequencies. If additional records of potential confounders become available, it is necessary to study the different trends of PWR based on the new information.

Additionally, we acknowledge that the large number of cohort participants may derive potentially biased discovery with overwhelmingly increased statistical power. However, we believe that this population-based approach is a powerful and inevitable tool for determining the patterns and trends on the large-scale cohorts and its statistically significant findings have its own informative value.

\section{Interpretation}

The exact causes underlying the observed increase in PWR are not thoroughly understood and identifying these causes will be important to facilitate the monitoring of weight gain by clinicians and to design effective weight management plans prior to conception, during pregnancy and postnatally for childbearing women. For instance, the prepregnancy BMIs and the smoking prevalence among women also showed a steady rise during the study period, suggesting that the temporal changes in these risk factors may have contributed to the observed increases in PWR. However, we confirmed that the increasing trend in PWR persisted after adjusting for both BMI and current smoking status, indicating that the trend may be either independent of or not fully explained by these risk factors. Further work is necessary to explore other environmental or social risk factors that were not examined in this study. One such factor is GWG, an important determinant for PWR. ${ }^{4}$ Between 2000 and 2009, the mean GWG among American women increased slightly, ${ }^{18}$ which may have contributed to the observed rise in PWR. Our study could not investigate the direct influence of GWG because the NHSE test did not explicitly measure maternal weight at delivery. It is not yet clear 
Table 4 Logistic regression analyses of the risk factors for a postpartum weight retention of more than $5 \mathrm{~kg}$

Crude OR $(95 \% \mathrm{CI})$

\begin{tabular}{|c|c|c|}
\hline Age (years) & 0.984 (0.980 to 0.988$)$ & 0.976 (0.972 to 0.980$)$ \\
\hline Pre-pregnancy time (month) & 1.072 (1.069 to 1.077$)$ & 1.022 (1.018 to 1.027$)$ \\
\hline Post-partum time (month) & 0.888 (0.884 to 0.891$)$ & 0.899 (0.895 to 0.904$)$ \\
\hline Pre-pregnancy BMI & 1.052 (1.047 to 1.057$)$ & 1.053 (1.048 to 1.059$)$ \\
\hline \multicolumn{3}{|l|}{ Income } \\
\hline Lowest quintile & 0.886 (0.846 to 0.927$)$ & 0.930 (0.886 to 0.975$)$ \\
\hline Second quintile & 1.036 (0.997 to 1.078$)$ & 1.018 (0.978 to 1.059$)$ \\
\hline Middle quintile & 1 & 1 \\
\hline Fourth quintile & 0.932 (0.905 to 0.959$)$ & 0.956 (0.928 to 0.985$)$ \\
\hline Highest quintile & 0.819 (0.782 to 0.858$)$ & 0.882 (0.840 to 0.925$)$ \\
\hline \multicolumn{3}{|l|}{ Year of delivery } \\
\hline 2003 & 1 & 1 \\
\hline 2004 & 1.481 (1.327 to 1.655$)$ & 1.103 (0.985 to 1.238$)$ \\
\hline 2005 & 1.539 (1.386 to 1.712$)$ & 1.231 (1.104 to 1.374$)$ \\
\hline 2006 & 1.582 (1.427 to 1.757$)$ & 1.213 (1.089 to 1.353$)$ \\
\hline 2007 & 1.558 (1.405 to 1.730$)$ & 1.246 (1.120 to 1.390$)$ \\
\hline 2008 & 1.783 (1.611 to 1.977$)$ & 1.379 (1.240 to 1.535$)$ \\
\hline 2009 & 1.663 (1.501 to 1.846$)$ & $1.329(1.194$ to 1.481$)$ \\
\hline 2010 & 1.635 (1.478 to 1.813$)$ & 1.261 (1.135 to 1.404$)$ \\
\hline 2011 & 1.749 (1.580 to 1.940$)$ & 1.383 (1.243 to 1.540$)$ \\
\hline 2012 & 1.827 (1.651 to 2.025$)$ & $1.440(1.296$ to 1.604$)$ \\
\hline \multicolumn{3}{|l|}{ Smoking status } \\
\hline Non-smoker & 1 & 1 \\
\hline Past smoker & $1.518(1.410$ to 1.634$)$ & $1.439(1.334$ to 1.551$)$ \\
\hline Current smoker & 1.406 (1.224 to 1.613$)$ & 1.414 (1.227 to 1.626$)$ \\
\hline
\end{tabular}

*Adjusted for variables in table 1 by multivariate logistic regression.

whether the secular rise in PWR is partially influenced by GWG or any associations between them.

Additional sensitivity analysis has been performed to verify the contribution of time since birth as a crucial determinant for the PWR trends. We ran the same statistical analyses after excluding women within 6 months of birth (online supplementary table 1,2). The result confirms the consistent pattern of weight gain after birth without women with recent birth, similar to our main findings. The findings comprehensively indicate the universal tendency of PWR increase over time, encompassing the broad ranges of time after birth from the study participants.

Other confounders that may influence PWR include the rates of breast feeding, changes in calorie intake, nurturing behaviours during pregnancy and exercise pattern. ${ }^{8101314}$ Recent prospective studies of the general Korean population reported that the breastfeeding rates in Korea have risen, ${ }^{19}$ and the overall total calorie intake has decreased by approximately 13\% from 1998 to 2010, while the number of people who exercise regularly has increased twofold over the same period. ${ }^{26}$ Therefore, further research should be performed to identify temporal variations among the other risk factors in population settings that were not covered in our dataset and to investigate how such changes may affect trends in PWR.

\section{CONCLUSION}

This is the first population-based study to present an increasing trend in PWR during the time period from 2003 to 2012, with an accompanying rise in the risks of experiencing a PWR greater than $5 \mathrm{~kg}$. Although we cannot ensure causality, several population-based confounding factors were suggested and incorporated into this analysis. Future systematic investigation are necessary to identify other practical implications underlying this trend. As obesity in pregnancy can have significant health implications for both mothers and babies, our study highlights the need to provide appropriate and effective weight management plans for women to reduce maternal/neonatal morbidity and pregnancy complications associated with increased weight. Promoting the healthy management of BMI and PWR may reduce 
Table 5 Results of linear mixed-effect model for the secular trends in postpartum weight retention

\begin{tabular}{|c|c|c|c|c|}
\hline & Estimates & SE & $95 \% \mathrm{CI}$ (lower) & $95 \% \mathrm{CI}$ (upper) \\
\hline Intercept & 54.174 & 0.08 & 54.017 & 54.33 \\
\hline \multicolumn{5}{|l|}{ Age } \\
\hline 30-40 years & -0.464 & 0.023 & -0.509 & -0.419 \\
\hline Over 40 years & -2.057 & 0.143 & -2.337 & -1.777 \\
\hline Prepregnancy BMI & 5.859 & 0.011 & 5.837 & 5.88 \\
\hline \multicolumn{5}{|l|}{ Income } \\
\hline Lowest quintile & -0.234 & 0.042 & -0.316 & -0.153 \\
\hline Second quintile & -0.203 & 0.036 & -0.273 & -0.133 \\
\hline Middle quintile & 0 (Ref) & & & \\
\hline \multicolumn{5}{|l|}{ Year of delivery } \\
\hline 2003 & 0 (Ref) & & & \\
\hline 2004 & 0.738 & 0.091 & 0.561 & 0.916 \\
\hline 2005 & 0.486 & 0.086 & 0.317 & 0.655 \\
\hline 2006 & 0.74 & 0.085 & 0.573 & 0.906 \\
\hline 2007 & 0.804 & 0.085 & 0.637 & 0.97 \\
\hline 2008 & 0.951 & 0.084 & 0.787 & 1.115 \\
\hline 2009 & 0.902 & 0.085 & 0.736 & 1.068 \\
\hline 2010 & 1.028 & 0.083 & 0.865 & 1.192 \\
\hline
\end{tabular}

*Time differences between prepregnancy and postpartum screening.

the population burden of pregnancy complications or maternal obesity and ultimately improve women's health through appropriate monitoring and intervention strategies to mitigate the continuous rise in PWR.

Contributors YYJ, SC and GJC designed the study. JHP collected and contributed the data. YYJ and GJC analysed the data and performed statistical analysis. YYJ, SC and GJC interpreted the results. YYJ and GJC drafted the manuscript. All authors critically reviewed the manuscript. SC and GJC jointly supervised this work.

Funding The authors have not declared a specific grant for this research from any funding agency in the public, commercial or not-for-profit sectors.

Competing interests None declared.

Patient consent for publication Not required.

Ethics approval The study protocol was approved by the Institutional Review Board of Korea University Medical Center (2016GR0090).

Provenance and peer review Not commissioned; externally peer reviewed.

Data availability statement Data may be obtained from a third party and are not publicly available. Our study used data from the National Health Insurance Service (NHIS), South Korea which does not permit public sharing of the data. However, all qualified researchers can apply for data access through the NHIS sharing service portal (https://nhiss.nhis.or.kr/).

Open access This is an open access article distributed in accordance with the Creative Commons Attribution Non Commercial (CC BY-NC 4.0) license, which permits others to distribute, remix, adapt, build upon this work non-commercially, and license their derivative works on different terms, provided the original work is properly cited, appropriate credit is given, any changes made indicated, and the use is non-commercial. See: http://creativecommons.org/licenses/by-nc/4.0/.

ORCID iD

Yoonjung Yoonie Joo http://orcid.org/0000-0001-9506-8742

\section{REFERENCES}

1 NCD Risk Factor Collaboration (NCD-RisC). Trends in adult bodymass index in 200 countries from 1975 to 2014: a pooled analysis of 1698 population-based measurement studies with $19 \cdot 2$ million participants. Lancet 2016;387:1377-96.

2 Kopelman PG. Obesity as a medical problem. Nature 2000;404:635-43.

3 Gore SA, Brown DM, West DS. The role of postpartum weight retention in obesity among women: a review of the evidence. Ann Behav Med 2003;26:149-59. 
4 Rooney BL, Schauberger CW. Excess pregnancy weight gain and long-term obesity: one decade later. Obstet Gynecol 2002;100:245-52.

5 Williamson DF, Madans J, Pamuk E, et al. A prospective study of childbearing and 10-year weight gain in US white women 25 to 45 years of age. Int J Obes Relat Metab Disord 1994;18:561-9.

6 Endres LK, Straub H, McKinney C, et al. Postpartum weight retention risk factors and relationship to obesity at 1 year. Obstet Gynecol 2015;125:144-52.

7 Linné Y, Barkeling B, Rössner S. Long-term weight development after pregnancy. Obes Rev 2002;3:75-83.

8 Krause KM, Lovelady CA, Peterson BL, et al. Effect of breastfeeding on weight retention at 3 and 6 months postpartum: data from the North Carolina WIC programme. Public Health Nutr 2010;13:2019-26.

9 Rong K, Yu K, Han X, et al. Pre-pregnancy BMI, gestational weight gain and postpartum weight retention: a meta-analysis of observational studies. Public Health Nutr 2015;18:2172-82.

10 Brandhagen M, Lissner L, Brantsaeter AL, et al. Breast-Feeding in relation to weight retention up to 36 months postpartum in the Norwegian mother and child cohort study: modification by socioeconomic status? Public Health Nutr 2014;17:1514-23.

11 Gunderson EP, Abrams B. Epidemiology of gestational weight gain and body weight changes after pregnancy. Epidemiol Rev 1999;21:261-75.

12 Gould Rothberg BE, Magriples U, Kershaw TS, et al. Gestational weight gain and subsequent postpartum weight loss among young, low-income, ethnic minority women. Am J Obstet Gynecol 2011;204:52.e1-52.e11. 52

13 Lyu L-C, Lo C-C, Chen H-F, et al. A prospective study of dietary intakes and influential factors from pregnancy to postpartum on maternal weight retention in Taipei, Taiwan. Br J Nutr 2009;102:1828-37.

14 Amorim AR, Linne YM, Lourenco PMC, et al. Diet or exercise, or both, for weight reduction in women after childbirth. Cochrane Database Syst Rev 2007;3:CD005627.

15 Endres LK, Straub H, McKinney C, et al. Community child health network of the Eunice Kennedy Shriver national institute of child health and human development. postpartum weight retention risk factors and relationship to obesity at 1 year. Obstet Gynecol 2015;125:144-52.

16 Fisher SC, Kim SY, Sharma AJ, et al. Is obesity still increasing among pregnant women? prepregnancy obesity trends in 20 states, 20032009. Prev Med 2013;56:372-8.

$17 \mathrm{Ng} \mathrm{M}$, Freeman MK, Fleming TD, et al. Smoking prevalence and cigarette consumption in 187 countries, 1980-2012. JAMA 2014;311:183-92.
18 Johnson JL, Farr SL, Dietz PM, et al. Trends in gestational weight gain: the pregnancy risk assessment monitoring system, 2000-2009. Am J Obstet Gynecol 2015;212:806.e1-806.e8.

19 Chung S-H, Kim H-R, Choi Y-S, et al. Trends of breastfeeding rate in Korea (1994-2012): comparison with OECD and other countries. $J$ Korean Med Sci 2013:28:1573-80.

20 Kachoria R, Moreland JJ, Cordero L, et al. Trends in breastfeeding initiation, continuation, and exclusivity by maternal prepregnancy weight: 2004-2011. Obesity 2015;23:1895-902.

21 Seong SC, Kim Y-Y, Park SK, et al. Cohort profile: the national health insurance service-national health screening cohort (NHIS-HEALS) in Korea. BMJ Open 2017;7:e016640.

22 Ohlin A, Rössner S. Maternal body weight development after pregnancy. Int J Obes 1990;14:159-73.

23 Korean national fitness assessment 2015. Korea Institute of sport science 2015. Available: https://www.sports.re.kr/flexer/ index.jsp?FileDir=/upload/site/www/plugin/board/48/201601/\& SystemFileName $=201601291342000100$.pdf\&ftype $=$ pdf $\&$ FileName=\%EA\%B5\%AD\%EB\%AF\%BC\%EC\%B2\%B4\%EB\% A0\%A5\%EC\%8B\%A4\%ED\%83\%9C\%EC\%A1\%B0\%EC\%82\%AC2015.pdf [Accessed 1 Jan 2020].

24 Pinheiro JC, Bates DM. Mixed-effects models in S and S-PLUS. New York: Springer, 2000.

25 Bates DM. Package 'Ime4: linear mixed-effects models using 'Eigen' and S4'. Version 1.1-18-1, (2018). Available: https://cran.r-project. org/web/packages/lme4/Ime4.pdf

26 Lim H, Kim SY, Wang Y, et al. Preservation of a traditional Korean dietary pattern and emergence of a fruit and dairy dietary pattern among adults in South Korea: secular transitions in dietary patterns of a prospective study from 1998 to 2010 . Nutr Res 2014;34:760-70.

27 Endres LK, Straub H, McKinney C, et al. Community child health network of the Eunice Kennedy Shriver National Institute of child health and human development. postpartum weight retention risk factors and relationship to obesity at 1 year. Obstet Gynecol 2015;125:144-52.

28 Connor Gorber S, Tremblay M, Moher D, et al. A comparison of direct vs. self-report measures for assessing height, weight and body mass index: a systematic review. Obes Rev 2007;8:307-26.

29 Waage CW, Falk RS, Sommer C, et al. Ethnic differences in postpartum weight retention: a Norwegian cohort study. BJOG 2016;123:699-708.

30 Cheng H-R, Walker LO, Tseng Y-F, et al. Post-partum weight retention in women in Asia: a systematic review. Obes Rev 2011;12:770-80. 